\title{
Metabolismo da videira 'syrah' no semiárido nordestino sob três estratégias hídricas
}

\section{Metabolism of 'Syrah' grapevine in the Brazilian semiarid northeast under three irrigation strategies}

\author{
Caio Márcio Guimarães Santos ${ }^{1 *}$; Márcia Moura Moreira ${ }^{2}$; João Domingos Rodrigues ${ }^{3}$
}

\section{Resumo}

Na região semiárida nordestina, na maioria das vezes, o fator limitante ao crescimento e desenvolvimento vegetal é a ausência quase na sua totalidade do recurso natural água e/ou a sua má distribuição. Neste contexto, o uso da técnica da irrigação se torna imprescindível como fator de produção essencial para um bom funcionamento do metabolismo primário e secundário das plantas. O presente trabalho teve o objetivo de avaliar o metabolismo da videira 'Syrah', sob três estratégias de irrigação no semiárido nordestino (Irrigação com Défice Controlado-IDC, Irrigação Deficitária-ID e Irrigação Plena-IP,). A pesquisa foi desenvolvida na Embrapa Semiárido, especificamente no Campo Experimental de Bebedouro, localizado no município de Petrolina-PE. O delineamento estatístico foi em blocos casualizados, em esquema fatorial $3 \times 6$. Foram utilizadas três estratégias de irrigação (IDC, ID e IP) e foram realizadas seis coletas ao longo do ciclo aos 54, 60, 73, 87, 101 e 115 dias após a poda (DAP). Foram avaliadas as variáveis: açúcares solúveis totais, açúcares redutores, proteína solúvel total e atividade das invertases. Realizou-se a análise de variância e o teste F para todas as variáveis, comparando as médias encontradas pelo teste de Tukey a 5\% de probabilidade. A irrigação deficitária confere maior atividade média da invertase ácida da parede ao final do ciclo. Os açúcares solúveis totais e açúcares redutores aumentam para todas as estratégias de irrigação ao final do ciclo. É possível reduzir o consumo de água nos cultivos vinícolas do semiárido nordestino sem afetar significativamente o metabolismo de proteínas e açúcares.

Palavras-chave: Carboidrato, défice hídrico, invertases, Vitis vinifera

\begin{abstract}
The almost complete absence or misdistribution of water as a natural resource frequently constitute a limiting factor for plant growth and development in the semi-arid northeastern Brazil. In this context, the use of appropriate irrigation techniques is an essential and indispensable factor for proper functioning of the primary and secondary metabolisms in plants. This study aimed to assess the metabolism of the Syrah grapevine in the semi-arid northeastern Brazil, by using three irrigation strategies (controlled deficit irrigation [CDI], deficit irrigation [DI], and full irrigation [FI]). The research was conducted at Embrapa Semiarid (Embrapa-Brazilian Agricultural Research Corporation), Experimental Field of Bebedouro, municipality of Petrolina, state of Pernambuco, Brazil. The statistical design was randomized blocks, with a $3 \times 6$ factorial scheme. Six samplings were performed throughout the experiment cycle at 54 , $60,73,87,101$, and 115 days after pruning (DAP). We analyzed the total soluble sugars, reducing
\end{abstract}

\footnotetext{
1 Prof. Dr. do Instituto Federal Sertão Pernambucano, IF Sertão PE, Campus Zona Rural, Petrolina, PE. E-mail: caio.santos@, ifsertao-pe.edu.br

2 Discente do curso de Pós-graduação em Solos e Qualidade de Ecossistemas, Universidade Federal do Recôncavo da Bahia, UFRB, Cruz das Almas, BA. E-mail: marcia.moureira@gmail.com

3 Prof. Dr. do Dept ${ }^{\mathrm{o}}$ de Botânica, Instituto de Biociências, Universidade Estadual Paulista Júlio de Mesquita Filho, UNESP, Botucatu, SP. E-mail: mingo@ibb.unesp.br

* Autor para correspondência
} 
sugars, total soluble protein, and invertase activity. Analysis of variance and the F test were performed for all analyzed variables. The means were compared using the Tukey test at $5 \%$ significance. At the end of the experiment cycle, DI was found to increase the average acid invertase activity in the plant cell wall. Further, by the end of the experiment cycle, the total soluble sugars and reducing sugars increased in all plants in the three irrigation strategies. Thus, we conclude that it is possible to reduce water consumption in vineyards of the semi-arid northeastern Brazil, without significantly affecting the protein and sugar metabolisms in the plants.

Key words: Carbohydrate, water deficit, invertases, Vitis vinifera

\section{Introdução}

Entre os ramos do setor agrícola em grande expansão está a fruticultura, com destaque para a região Nordeste, maior exportadora de frutas tropicais do país e de algumas frutas de clima temperado, a exemplo da uva. A uva de mesa cultivada, principalmente, no perímetro irrigado dos Estados de Pernambuco e Bahia é uma das frutas com maior valor agregado na exportação, tendo em vista o uso de tecnologias modernas de produção e a possibilidade de disponibilizar frutas no mercado internacional durante o período da entressafra dos maiores produtores mundiais.

A produção de carboidratos e certos fitoquímicos durante a formação, crescimento e maturação das bagas da uva é influenciada grandemente pelas condições edafoclimáticas, sendo o fornecimento de água um dos fatores que mais interferem na qualidade do fruto.

A restrição hídrica modifica o crescimento da baga (alongamento celular), diminuindo o volume celular (OJEDA; DELOIRE; CARBONNEAU, 2001), e isso pode promover maior e melhor relação película/polpa. Os frutos sujeitos à carência hídrica moderada apresentam maior quantidade dos compostos que estão presentes na película (tais como taninos e antocianinas), estando estes, geralmente, associados a um melhor potencial qualitativo (MATTHEWS; KRIEDEMANN, 2006). O défice hídrico moderado no período de maturação favorece o acúmulo de açúcares e compostos fenólicos, além de proporcionar cachos mais soltos, aerados e sadios, sendo fatores de grande importância para a elaboração de vinhos de qualidade (DELOIRE et al., 2004).
Todas as formas de produtos da videira têm origem nos açúcares produzidos nas folhas, através da fotossíntese e transportados tanto para os frutos, na época de produção, como para troncos, raízes e folhas não expandidas na fase vegetativa.

O défice hídrico quando severo é uma das principais barreiras à produtividade dos vinhedos, pois altera o metabolismo primário e secundário da videira, além de reduzir a qualidade e a produtividade de frutos. No entanto, a videira é uma planta relativamente tolerante ao estresse hídrico, em que um menor aporte de água dentro de um intervalo de tolerância (défice hídrico leve a moderado) e entre as fases de pintor e maturação pode conferir até mesmo características bioquímicas de qualidade aos frutos, como aumento no teor de açúcares e polifenóis (SOUZA, 2010).

O uso racional do recurso hídrico é necessário em regiões semiáridas partindo-se do princípio que a eficiência em seu uso confere maiores produções e produtividades, além de prevenir e/ou retardar um dos principais problemas nessas regiões que é o processo de salinização dos solos.

Atualmente, há necessidade de aprimoramento das práticas agronômicas que visem melhorar a qualidade da produção vinícola nordestina, uma vez que a composição da uva é um fator determinante para a qualidade dos vinhos. Todavia, pesquisas direcionadas ao suprimento hídrico e sua relação com a bioquímica dos frutos geram informações que facilitam e auxiliam a tomada de decisão dos vitivinicultores no melhor manejo da irrigação dos parreirais.

Considerando o exposto, o presente trabalho 
teve o objetivo de avaliar o metabolismo da videira 'Syrah' sob três estratégias de irrigação (IDCIrrigação com Défice Controlado, ID- Irrigação Deficitária e IP-Irrigação Plena) nas condições edafoclimáticas do Submédio do Vale do São Francisco.

\section{Material e Métodos}

O estudo de campo foi desenvolvido na Embrapa Semiárido, especificamente no Campo Experimental de Bebedouro, localizado no município de PetrolinaPE (latitude $9^{\circ} 09^{\prime}$ Sul, longitude $40^{\circ} 22^{\prime}$ ' Oeste, e altitude média de $365,5 \mathrm{~m}$ ), cujo clima segundo Köeppen pode ser classificado como tipo BSh, que corresponde a uma região semiárida muito quente. O solo da área em questão é classificado pelo Sistema Brasileiro de Classificação de Solos como Argissolo Vermelho Amarelo Eutrófico Latossólico, textura média.

A videira 'Syrah' foi enxertada sobre o portaenxerto '1103 Paulsen', sendo que as mudas do porta-enxerto foram obtidas por meio de estaquia. $\mathrm{O}$ espaçamento foi de $1 \mathrm{~m}$ entre plantas e $3 \mathrm{~m}$ entre fileiras, ocupando uma área útil de $81 \mathrm{~m}^{2}$ e a condução das plantas feita no sistema de espaldeira (com três fios de arame) em cordão bilateral e a poda de produção adotada foi em esporão, deixando-se duas gemas por esporão e cinco a seis esporões por planta. O sistema de irrigação utilizado foi o de gotejamento com emissores espaçados em 0,5 $\mathrm{m}$ na linha de plantas. Com a poda de produção acompanhou-se as fases fenológicas de acordo com a escala de Baillod e Baggiolini (1993). A partir da iniciação da fase fenológica ' $L$ ' (45 dias após a poda de produção-DAP), teve início a aplicação dos tratamentos de irrigação: 1- Irrigação Plena (IP), sem restrição de água às videiras durante todo o ciclo de produção, sendo a irrigação feita para repor a lâmina correspondente à evapotranspiração da cultura (ETc); 2 - Irrigação Deficitária (ID), onde a aplicação de água foi interrompida desde a fase fenológica de cacho fechado até cacho maduro;
3 - Irrigação com Défice Controlado (IDC), onde a aplicação de água foi interrompida desde a fase fenológica de cacho fechado, mas a irrigação foi realizada aos 70, 71, 87 e 90 dias, respectivamente após a poda, para o aumento da umidade do solo na profundidade efetiva do sistema radicular $(0,6$ $\mathrm{m})$. O momento da irrigação foi decidido conforme o monitoramento semanal da umidade do solo nas profundidades de 0,$15 ; 0,30 ; 0,45$ e $0,60 \mathrm{~m}$ pela técnica de moderação de nêutrons (sonda de nêutrons).

O manejo de irrigação foi realizado com base na evapotranspiração de referência (ETo, mm) e em coeficientes de cultura $(\mathrm{Kc})$.

Para a realização das análises bioquímicas coletou-se a folha oposta ao cacho. Após a coleta das folhas foram quantificados os açúcares solúveis totais pelo método proposto por Morris (1948), os açúcares redutores pelo método proposto por Miller (1959) e a extração e ensaio das invertases foi realizada conforme metodologia proposta por Silva et al. (2003) com algumas modificações.

A determinação do teor de proteína solúvel total foi realizada de acordo com o método proposto por Bradford (1976) utilizando o mesmo extrato obtido para a determinação dos açúcares.

O delineamento estatístico foi em blocos casualizados, em esquema fatorial $3 \times 6$, sendo utilizadas três estratégias de irrigação (IP, IDC e ID) e realizadas seis coletas foliares ao longo do ciclo, aos 54, 60, 73, 87, 101 e 115 dias após a poda (DAP), com nove repetições. Realizou-se a análise de variância e o teste $\mathrm{F}$ ( $\mathrm{p}<0,01)$, comparando-se as médias pelo teste de Tukey a 5\% de probabilidade.

\section{Resultados e Discussão}

Na Tabela1 encontram-se os dados referentes às médias estatísticas para o teor de proteína solúvel

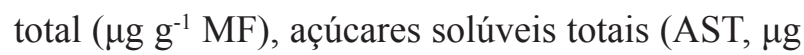
$\mathrm{g}^{-1}$ de $\mathrm{MF}$ ) e açúcares redutores (AR, $\mu \mathrm{g} \mathrm{g}^{-1}$ de $\mathrm{MF}$ ) aos 54, 60, 73, 87, 101 e 115 dias após a poda; cujos 
resultados mostram que houve resposta significativa apenas entre os diferentes dias após a poda.

Verifica-se que aos 54 e 60 DAP não houve diferença significativa no teor de proteína solúvel total (PST). Contudo, aos 73 DAP, o teor de PST apresentou respostas significativas com incremento de 55 e $43 \%$ em relação às duas primeiras coletas, respectivamente.

Uma resposta fisiológica específica ao défice hídrico representa na verdade combinações de eventos moleculares que são ativados ou desativados pela percepção ao estresse. Hsiao (1990) relatou que quando as plantas estão submetidas ao défice hídrico ocorrem alterações no metabolismo e na estrutura celular, notadamente na redução da síntese de proteínas, devido à síntese de proteases, com aumento da concentração de aminoácidos livres especialmente a L-prolina. Outros autores relatam que algumas plantas sob condições de estresse hídrico alteram seu metabolismo acumulando solutos orgânicos (NAIDU; PALEG; JONES, 1992). Entre estes solutos estão proteínas que participam diretamente do metabolismo vegetal, designadas de proteínas solúveis. Todos os tipos de estresse causam alterações na expressão gênica, as quais se manisfestam na indução ou repressão de proteínas expressadas em condições normais (PAZ; AGUIRRE; ONTIVEROS, 2001). Algumas proteínas envolvidas na interação hidrofílica com macromoléculas celulares são sintetizadas para estabelecer o metabolismo e agir na recuperação dos danos causados pelo estresse hídrico (LOBATO et al., 2008).

O défice hídrico pode produzir efeitos no metabolismo das plantas, levando ao acúmulo ou perda de metabólitos como carboidratos, ácidos orgânicos, ácido abscísico (ABA) e aminoácidos, além de alterar a atividade de enzimas e síntese de proteínas. O acúmulo de metabólitos em plantas (ajustamento osmótico) sob défice hídrico proporciona redução do potencial osmótico mediante aumento líquido na concentração de solutos intracelulares (CHAVES, 1991). Esse ajustamento pode auxiliar a planta a manter o turgor, sustentando, dessa maneira, o influxo de água para o crescimento celular.

Santos, Lima e Morgado (2010) concordando com as informações dos autores citados no parágrafo anterior, observaram aumento de proteínas em genótipos de feijão sob deficiência hídrica e atribuíram à alteração do potencial osmótico da célula para evitar a perda de água para o meio. A síntese de osmólitos, incluindo prolina, é amplamente usada por plantas para estabilizar as membranas e manter a conformação das proteínas sob baixo potencial hídrico (EFEOGLU; EKMEKÇI; ÇIÇEK, 2008).

A síntese e o acúmulo de solutos orgânicos e/ou inorgânicos variam entre espécies vegetais, assim como em diferentes cultivares da mesma espécie. A prolina é também conhecida por estar envolvida em reduzir danos nos tilacóides das membranas, agindo como um eliminador de radicais livres, além de marcador bioquímico entre espécies e para genótipos dentro da mesma espécie sob estresse hídrico (SANTOS; LIMA; MORGADO, 2010).

O resultado obtido aos 73 DAP indicou que nessa avaliação a produção de compostos nitrogenados foi significativamente, mais eficiente que todas as outras datas de coletas. O potencial hídrico foliar de base $(\Psi \mathrm{b})$ mais próximo dessa avaliação, aos 70 DAP (-0,243 MPa) indicou que as plantas estavam sob défice hídrico leve. Segundo Kirschbaum (1988) trabalhando com Eucalyptus pauciflora sugeriu que a recuperação de plantas sob défice hídrico requer a síntese de novo de proteínas fotossintéticas. Nessa mesma vertente, Bogeat-Triboulot et al. (2007) mostraram que a recuperação ao défice hídrico para plantas de Populus euphratica foi acompanhada pelo aumento de algumas proteínas fotossintéticas, particularmente a Rubisco. Acredita-se que plantas no presente estudo aos 73 DAP tenham tido comportamento semelhante ao das duas espécies vegetais citadas anteriormente. Uma maior síntese de proteínas fotossintéticas pode ser confirmada 
com a geração de maior atividade fotossintética. Isto ocorreu aos 73 DAP com a média da taxa de assimilação líquida de $17,53 \mu \mathrm{mol} \mathrm{m} \mathrm{m}^{-2} \mathrm{~s}^{-1}$ (dados não apresentados), registrando incremento fotossintético de aproximadamente $29 \%$ em relação à coleta anterior. Este resultado também condiz com a fase fenológica, uma vez que a partir dessa data já se verificava início do 'pintor' que é uma fase de grande requisito metabólico para as folhas.

O teor de PST nas folhas em relação às diferentes estratégias de irrigação aumentou até o início da fase fenológica de 'pintor' (73 DAP), com tendência decrescente após essa fase. Este resultado está relacionado com os maiores valores de assimilação de $\mathrm{CO}_{2}$ obtidos durante essa avaliação. Pois, entre as proteínas solúveis totais presentes nas folhas, a Rubisco é uma das mais expressivas. $\mathrm{O}$ aumento no teor de proteínas do complexo fotossintético pode justificar as altas taxas significativas de fotossíntese registradas para todas as estratégias hídricas nessa avaliação.

A partir dos 87 até os 115 DAP, mesmo com as variações no $\Psi \mathrm{b}$ (dados não apresentados), não houve diferença significativa no teor de PST nessas coletas. Alguns autores afirmam que o teor de proteínas pode aumentar com a síntese de novo (KIRSCHBAUM, 1988; BOGEAT-TRIBOULOT et al., 2007) ou diminuir pela ação de proteases ou proteólise (KALA; GODORA, 2011) em função do défice hídrico. Além disso, o consumo ou produção de proteínas vai estar relacionado ao nível de estresse, sendo a expressão gênica o fator determinante para a recuperação ao estresse de uma forma menos dispendiosa à manutenção do crescimento e desenvolvimento celular.

Os teores de glicose, frutose e sacarose, bem como a atividade de enzimas do metabolismo de carboidratos em folhas de videiras, são influenciados por variações sazonais e fenológicas das videiras (PALLIOTTI; CARTECHINI, 2001).

Os açúcares provenientes da fotossíntese agem como substrato para o metabolismo energético e biossíntese de carboidratos, fornecendo condições de crescimento e desenvolvimento aos tecidos dreno. Além disso, os açúcares podem funcionar como mensageiros secundários assegurando que a planta continue a se desenvolver, mesmo após estresses bióticos ou abióticos (HAMMOND; WHITE, 2008).

As plantas das três estratégias hídricas apresentaram aumento semelhante no teor de açúcares solúveis totais e redutores em suas folhas na fase de maturação de frutos ao longo das avaliações. Esse aumento gradual nos açúcares era esperado como já definido por muitos autores (DANTAS et al., 2005; DANTAS; RIBEIRO; PEREIRA, 2007; DANTAS et al., 2007) em relação ao crescimento e desenvolvimento dos frutos da videira em função do acúmulo de fotoassimilados provenientes das folhas.

As diferentes estratégias hídricas estudadas não diferenciaram estatisticamente entre si. Outros autores (BASSOI et al., 2007; DANTAS et al., 2007; SOUZA et al., 2009) avaliando na mesma região diferentes estratégias de irrigação e portaenxertos não encontraram influências dos diferentes manejos nas características avaliadas. Desta forma, as restrições hídricas impostas às plantas através dos tratamentos IDC e ID não foram limitantes à produção de açúcares pelas folhas.

Os maiores valores médios de açúcar solúvel total (AST) nas folhas da videira foram obtidos nas duas últimas coletas (101 e 115 DAP) coincidindo com a fase de amadurecimento de bagas, quando há maior produção e translocação de carboidratos das folhas fontes para nutrir os cachos.

Jain et al. (2002) estudaram o padrão de acúmulo de açúcar em genótipos de videira muscadínias e definiram que o maior requerimento em açúcar nas folhas pelos órgãos dreno ocorrem após o veraison (amadurecimento das bagas) e durante o florescimento. No entanto, alguns estudos relatam que o aumento no teor de açúcar na folha pode reduzir a atividade fotossintética e a condutância 
estomática, devido a deformação nos tilacóides, deficiência em fosfato inorgânico (Pi) causada pela inibição da síntese de sacarose ou devido a enzimas do ciclo de Calvin (STITT; VON SCHAEWEN; WILLMITZER, 1990). No entanto, os processos fisiológicos em folhas parecem ser regulados para restaurar e manter um equilíbrio entre fotossíntese e exportação de carbono assimilado (QUEREIX, 2001).

Durante a fase de maturação, a sacarose é convertida em monossacarídeos que vão se acumulando progressivamente nas bagas (ALI et al., 2010). A relação entre a fotossíntese e a disponibilidade hídrica foi variável no presente estudo, descartando a hipótese de que quanto maior a disponibilidade de água maior a produção e qualidade de frutos para o processamento. No entanto, esperava-se que o tratamento IP tivesse maior influência na concentração de açúcares nas folhas e/ou frutos, considerando suas maiores taxas fotossintéticas, mas isso não foi verificado. Confirmando assim, a importância do uso do défice hídrico nos atributos de qualidade em videiras, sendo um dos assuntos mais pesquisados em vinhedos em todas as regiões do globo terrestre com características semiáridas a áridas. Todavia, a importância do uso da deficiência hídrica nas plantas vem como uma forma de estimulá-las a metabolizarem com o máximo de eficiência e economia dos recursos hídricos não limitantes.

$\mathrm{Na}$ irrigação com défice hídrico controlado a quantidade de açúcar solúvel total variou de 1685 $\mu \mathrm{g} \mathrm{g}^{-1} \mathrm{MF}$ aos 54 DAP a $2306 \mu \mathrm{g} \mathrm{g}^{-1}$ MF no dia da colheita, o que representou incremento ao longo do ciclo de $27 \%$. No entanto, comparando o resultado obtido aos 87 DAP com o da colheita se observa incrementos de até $46 \%$ entre essas datas. Isso indica que o teor de açúcares solúveis totais nas folhas ao longo do ciclo é muito variável, pois dependerá da fase fenológica da planta, o seu estado nutricional e as condições atmosféricas.

A irrigação plena promoveu aumentos de até $47 \%$ na quantidade de açúcar solúvel total nas folhas durante o ciclo, variando de 1.171,67 $\mu \mathrm{g} \mathrm{g}^{-1} \mathrm{MF}(87$ DAP) a $2.229 \mu \mathrm{g} \mathrm{g}^{-1} \mathrm{MF}$ (115 DAP). A irrigação deficitária promoveu incrementos menores (36\%) em relação aos outros tratamentos.

Os principais açúcares redutores presentes nas folhas e frutos da videira são a glicose e a frutose, encontrados, principalmente, na fase de maturação.

Observa-se aumento nos valores médios de açúcares redutores nas folhas ao longo do ciclo em todas as três estratégias hídricas estudadas, com seu ápice na última avaliação realizada aos 115 DAP.

As diferentes disponibilidades de água às plantas durante o ciclo não apresentaram diferenças significativas em cada uma das avaliações realizadas até 115 DAP. Contudo, quando se analisou as estratégias hídricas separadamente nas seis datas distintas, notou-se que os mesmos influenciaram no maior ou menor volume de açúcares redutores nas folhas. Isso era esperado, partindo do princípio de que com o avanço do ciclo fenológico das plantas o volume de carboidratos requisitados pelos diferentes órgãos vegetais aumenta o que demanda maior consumo hídrico.

A disponibilidade hídrica fornecida pelos tratamentos IDC, ID e IP entre 54 e 115 DAP contribuíram com cerca de 35, 29 e 30\%, respectivamente, no aumento do volume de açúcares redutores nas folhas ao longo do ciclo. Notou-se também, que os maiores incrementos no conteúdo de açúcares redutores ocorreram entre os 87 e 115 DAP nas três estratégias de irrigação, com acréscimos de 53,51 e $40 \%$ na IP, IDC e ID, respectivamente.

Esses resultados aparentemente discordantes refletem a complexidade dos mecanismos de ação da disponibilidade hídrica em relação à concentração de açúcares. O tratamento IP ao final do ciclo apresentou conteúdos de açúcares semelhantes aos demais tratamentos com restrições hídricas, podendo boa parte dos seus fotoassimilados terem sido desviados para a atividade vegetativa e/ou armazenamento nos ramos, raízes e braços durante o período de 
pós-veraison, desviando assim, os açúcares que se acumulariam nas bagas (KOUNDOURAS et al., 2006). Essa afirmação ainda pode ser confirmada por não ter havido diferença no teor de sólidos solúveis entre as estratégias hídricas na colheita e um maior crescimento vegetativo para o tratamento IP foi visualizado na área experimental. Este resultado confirma a importância do uso de técnicas com défice hídrico, onde pode-se obter bons resultados de qualidade na produção com economia e eficiência no uso da água.

O período de 54 a 87 DAP coincidiu com as maiores taxas de fotossíntese, consequentemente, maior exportação de carboidratos produzidos para os principais drenos (meristema apical, cacho e ramos). Desta forma, era de se esperar menor acúmulo nas folhas durante esse período. Esses resultados estão de acordo com os obtidos por Dantas et al. (2005); Dantas, Ribeiro e Pereira (2007), onde o acúmulo de açúcares nas folhas aumenta durante o início da maturação, porém, é fortemente influenciado pelas variações climáticas.

Desta forma, o défice hídrico suave a moderado pode influenciar na arquitetura da planta, reduzindo o seu porte e/ou crescimento dos ramos, promovendo melhor aproveitamento das trioses-P geradas no ciclo de Calvin para constituir os carboidratos de reserva e estruturais, além de compostos nitrogenados essenciais para a constituição e ativação enzimática.

$\mathrm{Na}$ Tabela 1, além dos resultados estatísticos ao longo do ciclo para PST, AST e AR são apresentadas também, as atividades das enzimas invertases com comportamentos significativos variados entre as mesmas.

Tabela 1. Teor ( $\left.\mu \mathrm{g} \mathrm{g}^{-1} \mathrm{MF}\right)$ de proteína solúvel total (PST,), açúcar solúvel total (AST), açúcar redutor (AR) e atividade das enzimas ( $\mu \mathrm{mol} \mathrm{g}^{-1} \mathrm{MF} \mathrm{h}^{-1}$ ): invertase neutra do citossol (INC), invertase ácida do vacúolo (IAV) e invertase ácida da parede (IAP) em folhas de videira 'Syrah' ao longo do ciclo em função de três estratégias de irrigação (Irrigação com défice controlado-IDC, Irrigação deficitária-ID e Irrigação plena-IP). Embrapa Semiárido - Petrolina, PE, 2010.

\begin{tabular}{|c|c|c|c|c|}
\hline Dias após a poda & & égia de irrig & & \\
\hline & IDC & ID & IP & Média \\
\hline & \multicolumn{4}{|c|}{ Teor de proteína solúvel total $\left(\mu \mathrm{g} \mathrm{g}^{-1} \mathrm{MF}\right)$} \\
\hline 54 & 168,66 & 244,13 & 226,64 & $213,14 \mathrm{c}$ \\
\hline 60 & 281,22 & 283,92 & 248,47 & $271,20 \mathrm{bc}$ \\
\hline 73 & 443,54 & 550,00 & 429,69 & $474,41 \mathrm{a}$ \\
\hline 87 & 309,27 & 270,07 & 255,40 & $278,25 \mathrm{bc}$ \\
\hline 101 & 294,49 & 297,42 & 269,72 & $287,21 b c$ \\
\hline 115 & 315,77 & 302,53 & 300,56 & $306,29 \mathrm{~b}$ \\
\hline \multirow[t]{2}{*}{ Média } & $302,16 \mathrm{~ns}$ & $324,68 \mathrm{~ns}$ & $288,41 \mathrm{~ns}$ & \\
\hline & \multicolumn{4}{|c|}{ Açúcar solúvel total (AST, $\mu \mathrm{g} \mathrm{g}^{-1}$ de MF) } \\
\hline 54 & 1685,00 & 1571,58 & 1669,75 & $1642,11 b c$ \\
\hline 60 & 1574,08 & 1616,25 & 1562,17 & $1584,17 \mathrm{c}$ \\
\hline 73 & 1492,33 & 1494,75 & 1515,92 & $1501,00 \mathrm{c}$ \\
\hline 87 & 1240,17 & 1353,25 & 1171,67 & $1255,03 \mathrm{~d}$ \\
\hline 101 & 1956,50 & 1813,67 & 1725,67 & $1831,95 b$ \\
\hline 115 & 2306,60 & 2128,00 & 2229,00 & $2221,20 \mathrm{a}$ \\
\hline Média & $1709,11 \mathrm{~ns}$ & $1662,92 \mathrm{~ns}$ & $1645,86 \mathrm{~ns}$ & \\
\hline
\end{tabular}

continua 
continuação

\begin{tabular}{|c|c|c|c|c|}
\hline & \multicolumn{4}{|c|}{ Açúcar redutor (AR, $\mu \mathrm{g} \mathrm{g}^{-1}$ de $\left.\mathrm{MF}\right)$} \\
\hline 54 & 185,32 & 177,61 & 181,49 & $181,51 b$ \\
\hline 60 & 168,02 & 175,91 & 166,09 & $170,01 \mathrm{~b}$ \\
\hline 73 & 157,69 & 162,93 & 156,94 & $159,19 \mathrm{bc}$ \\
\hline 87 & 140,21 & 152,16 & 120,84 & $137,74 \mathrm{c}$ \\
\hline 101 & 174,01 & 163,93 & 153,42 & $163,79 b c$ \\
\hline 115 & 284,94 & 248,82 & 258,78 & $264,18 \mathrm{a}$ \\
\hline \multirow[t]{2}{*}{ Média } & $185,03 \mathrm{~ns}$ & $180,22 \mathrm{~ns}$ & $172,93 \mathrm{~ns}$ & \\
\hline & \multicolumn{4}{|c|}{ Atividade da enzima invertase neutra do citossol (INC, $\left.\mu \mathrm{mol} \mathrm{g}^{-1} \mathrm{MF} \mathrm{h}^{-1}\right)$} \\
\hline 54 & 24,03 & 23,85 & 20,58 & $22,82 \mathrm{~ns}$ \\
\hline 60 & 23,39 & 31,09 & 30,73 & $28,40 \mathrm{~ns}$ \\
\hline 73 & 29,54 & 26,23 & 28,14 & $27,97 \mathrm{~ns}$ \\
\hline 87 & 17,95 & 24,75 & 33,99 & $25,56 \mathrm{~ns}$ \\
\hline 101 & 37,66 & 31,07 & 21,73 & $30,15 \mathrm{~ns}$ \\
\hline 115 & 32,48 & 23,51 & 32,37 & $29,45 \mathrm{~ns}$ \\
\hline \multirow[t]{2}{*}{ Média } & $27,50 \mathrm{~ns}$ & $26,75 \mathrm{~ns}$ & $27,92 \mathrm{~ns}$ & \\
\hline & \multicolumn{4}{|c|}{ Atividade da enzima invertase ácida do vacúolo (IAV, $\mu \mathrm{mol} \mathrm{g}^{-1} \mathrm{MF} \mathrm{h}^{-1}$ ) } \\
\hline 54 & 32,29 & 31,74 & 25,58 & $29,87 \mathrm{abc}$ \\
\hline 60 & 23,24 & 21,62 & 23,14 & $22,67 \mathrm{c}$ \\
\hline 73 & 29,06 & 29,41 & 25,84 & $28,10 \mathrm{bc}$ \\
\hline 87 & 26,70 & 24,75 & 25,51 & $25,65 \mathrm{c}$ \\
\hline 101 & 40,95 & 32,91 & 33,61 & $35,82 \mathrm{ab}$ \\
\hline 115 & 31,62 & 45,81 & 37,55 & $38,33 \mathrm{a}$ \\
\hline \multirow[t]{2}{*}{ Média } & $30,64 \mathrm{~ns}$ & $31,04 \mathrm{~ns}$ & $28,54 \mathrm{~ns}$ & \\
\hline & \multicolumn{4}{|c|}{ Atividade da enzima invertase ácida da parede (IAP, $\mu \mathrm{mol} \mathrm{g}^{-1} \mathrm{MF} \mathrm{h}^{-1}$ ) } \\
\hline 54 & 27,19 & 25,74 & 21,88 & $24,94 \mathrm{c}$ \\
\hline 60 & 29,95 & 50,00 & 27,89 & $35,95 \mathrm{ab}$ \\
\hline 73 & 40,66 & 39,47 & 36,62 & $38,92 \mathrm{a}$ \\
\hline 87 & 29,12 & 33,79 & 28,72 & $30,54 \mathrm{bc}$ \\
\hline 101 & 26,81 & 30,31 & 26,27 & $27,80 \mathrm{c}$ \\
\hline 115 & 29,90 & 33,00 & 29,05 & $30,65 \mathrm{bc}$ \\
\hline Média & $30,64 \mathrm{~B}$ & $35,39 \mathrm{~A}$ & $28,40 \mathrm{~B}$ & \\
\hline
\end{tabular}

Médias seguidas de mesma letra minúsculas na coluna e maiúsculas na linha, não diferem entre si pelo teste Tukey a 5\% de probabilidade; ns: não significativo.

Fonte: Elaboração dos autores.

As invertases são isoenzimas responsáveis pela hidrólise da sacarose, principal carboidrato translocável nas plantas superiores, em D-glicose e D-frutose que desempenham papel fundamental no metabolismo primário do carbono (BARRATT et al., 2009) e desenvolvimento das plantas. As invertases são classificadas nas isoformas: vacuolar (IAV), citoplasmática (INC) e apoplástica (Parede celular) (IAP) e compartilham algumas propriedades bioquímicas comuns (STURM, 1999).
Não houve resposta significativa para a atividade da invertase neutra do citossol (INC) nas diferentes estratégias de irrigação e nem para as diferentes avaliações ao longo do ciclo. A invertase ácida do vacúolo (IAV) apresentou respostas significativas apenas para as diferentes datas de avaliação. Contudo as diferentes estratégias hídricas, assim como as datas de coleta durante o ciclo promoveram respostas significativas para a atividade da invertase ácida da parede celular (IAP). 
Diferentemente da IAV e IAP poucas informações sobre o papel da INC nas plantas estão disponíveis na literatura. Alguns pesquisadores atribuem isso à sua alta instabilidade e baixa atividade (RUAN; LLEWELLYN; FURBANK, 2003). Entretanto, estudos recentes revelam que a INC possa compensar a perda da atividade da sacarose sintase em mutantes de Arabidopsis (BARRATT et al., 2009); no entanto, em drenos fortes como sementes de milho e fibras de algodão (RUAN; LLEWELLYN; FURBANK, 2003) isso não foi verificado.

Os maiores valores médios significativos para a atividade da IAV foram obtidos na colheita aos 115 DAP, com incrementos de 41 e 33\% em relação aos 60 e 87 DAP. Porém, a atividade da enzima aos 115 DAP não se diferenciou estatisticamente das coletas aos 54 e 101 DAP. Esse comportamento oscilante da atividade da enzima é esperado, pois os processos bioquímicos são dinâmicos e podem ser afetados, instantaneamente, por muitos fatores endógenos e ambientais. No entanto, esses resultados podem indicar que durante o período de avaliação, a maior requisição da atividade dessa enzima durante o ciclo seria nos estádios finais de maturação, onde ocorre maior clivagem da sacarose, produzindo, principalmente, os monossacarídeos glicose e frutose. Assim, consequentemente, o aumento da atividade da IAV provoca nessa fase, aumento na concentração de açúcares redutores nas folhas. Intensa atividade da invertase tem sido encontrada em bagas maduras de uva e a acumulação de açúcar no fruto durante a maturação tem mostrado correlacão com a alta atividade da invertase (DAVIES; ROBINSON, 1996).

A expressão e a distribuição de invertases em plantas são bastante estudadas, devido ao seu importante papel no metabolismo do açúcar (ENDO et al., 1990). Peter e Stephanie (1994) relataram que a atividade da invertase está positivamente correlacionada com o acúmulo de açúcares redutores em tomates. Em estudos anteriores com uvas brancas notou que a invertase se encontrava sob duas formas: a ligada e a solúvel. Atualmente, é sabido que as plantas apresentam três isoformas de invertases, a IAV, IAP e INC, todas com diferentes localizações nas células, mas, com propriedades bioquímicas comuns (STURM, 1999).

Geralmente, acredita-se que IAV possa controlar a expansão celular pela regulação osmótica (SERGEEVA et al., 2006). Isto é conseguido pela hidrólise da sacarose em duas moléculas de monossacarídeos, duplicando assim, na contribuição osmótica, facilitando o influxo de água para impulsionar a expansão das células. Essa pode ser também uma das alternativas das plantas sob défice hídrico, para regular seu potencial hídrico interno. Isto pode ter ocorrido com maior frequência nos tratamentos IDC e ID durante o ciclo.

A IAV hidrolisa a sacarose no vacúolo e sua atividade tem alta correlação com o acúmulo de hexoses em vários órgãos, além de controlar a composição do açúcar, como registrado para tomate, uva e tubérculo de batata (GREINER et al., 1999). Alta expressão ou atividade da IAV tem sido relatada na expansão de tecidos de tubérculo de batata (ROSS et al., 1994), raízes de cenoura (TANG; LUSCHER; STURM, 1999), ovários de milho (ANDERSEN et al., 2002) e raízes e hipocótilos de Arabidopsis (SERGEEVA et al., 2006). A invertase não tem apenas o papel de suprir em carbono as plantas, mas também na sinalização do açúcar e no desenvolvimento (RUAN et al., 2010).

Os valores médios da atividade da IAP para as estratégias de irrigação estabelecidas se diferenciaram estatisticamente ao final do ciclo, com destaque para a irrigação deficitária que apresentou 13 e $20 \%$ a mais de atividade da enzima em relação às estratégias IDC e IP na devida ordem. Além disso, no tratamento ID após o pico $\left(50 \mu \mathrm{mol} \mathrm{g}^{-1} \mathrm{MF} \mathrm{h}^{-1}\right)$ de atividade, iniciou-se nas avaliações posteriores, queda progressiva até a colheita. As invertases possuem limitado envolvimento no crescimento radicular, mas atuam na osmorregulação, expansão celular e canalização da sacarose no metabolismo (TANG; LUSCHER; STURM, 1999). Este fato 
poderia caracterizar a maior atividade da IAP aos 60 DAP na estratégia de irrigação ID em relação aos demais tratamentos. Durante o descarregamento do floema nos drenos, a sacarose pode ser transportada pela via apoplástica (através da matriz da parede celular) ou simplástica (através dos plasmodesmos) sendo a IAP uma das mais ativas. Alguns trabalhos relatam a importância da IAP no desenvolvimento floral (ZANOR et al., 2009), de sementes (JIN; NI; RUAN, 2009) e frutos (ZANOR et al., 2009). Além disso, algumas pesquisas relatam que a alta atividade da IAP é um componente essencial para o atraso da senescência foliar mediada pelo hormônio vegetal citocinina (LARA et al., 2004). Isso pode ter ocorrido no presente experimento, em função dos valores médios da atividade da IAP aos 54 e aos 115 DAP não terem se diferenciado estatisticamente. Todavia estudos recentes de Jin, Ni e Ruan (2009) revelaram que a redução da atividade da IAP pode levar a uma baixa relação sacarose/hexose no apoplasto foliar podendo provocar ou permitir a senescência, devido a expressão do gene da protease-CYS induzido pelo ABA.

O tratamento IP teve comportamento parecido ao anterior, em que após ter registrado no decorrer do ciclo o menor valor da atividade da enzima IAP $\left(21,88 \mu \mathrm{mol} \mathrm{g}{ }^{-1} \mathrm{MF} \mathrm{h}^{-1}\right)$ aos 54 DAP, apresentou comportamento variável nos demais dias de avaliação, obtendo o seu pico $\left(36,62 \mu \mathrm{mol} \mathrm{g} \mathrm{g}^{-1} \mathrm{MF}\right.$ $\mathrm{h}^{-1}$ ) aos 73 DAP, na qual a data coincidiu com intervalos de maiores potenciais hídricos foliares de base e taxas de assimilação para esse tratamento.

O processo de acumulação de açúcares em bagas de uva ainda não está completamente elucidado e, embora, a invertase solúvel possa ter importante papel na acumulação de hexoses no vacúolo, a sua síntese não parece estar relacionada a esse acúmulo (DREIER; HUNTER; RUFFNER, 1998). Outros mecanismos devem estar envolvidos na regulação do acúmulo de açúcares, tais como a diferença de potencial hídrico entre a fonte e o dreno o que favorece o movimento da seiva do floema para as bagas. Além disso, o carregamento de açúcares no floema pode ser afetado pelo estresse hídrico (WANG et al., 2003).

Os resultados obtidos no presente estudo concordam com os obtidos por Dantas et al. (2005). Além disso, a maior atividade média da IAP na estratégia ID ao final do ciclo em relação à IDC e IP caracteriza maior transporte de sacarose fotossintética pela via apoplástica das células.

Desta forma, as diferentes invertases (INC, IAV e IAP) presentes nas células foliares, além de se diferenciarem na localização celular, também se diferenciam na atividade ao longo do ciclo metabólico das plantas, quando submetidas às diferentes estratégias hídricas.

\section{Conclusões}

A irrigação deficitária confere maior atividade média da invertase ácida da parede ao final do ciclo.

Os açúcares solúveis totais e açúcares redutores aumentam para todas as estratégias de irrigação ao final do ciclo.

É possível reduzir o consumo de água nos cultivos vinícolas do semiárido nordestino sem afetar significativamente o metabolismo de proteínas e açúcares.

\section{Referências}

ALI, K.; MALTESE, F.; CHOI, Y. H.; VERPOORTE, R. Metabolic constituents of grapevine and grape-derived products. Phytochemistry Reviews, Dordrecht, v. 9, n. 3, p. 357-378, 2010.

ANDERSEN, M. N.; ASCH, F.; WU, Y.; JENSEN, C. R.; NAESTED, H.; MOGENSEN, V. O.; KOCH, K. E. Soluble invertase expression is an early target of drought stress during the critical, abortion-sensitive phase of young ovary development in maize. Plant Physiology, Minneapolis, v. 130, n. 2, p. 591-604, 2002.

BAILLOD, M.; BAGGIOLINI, M. Lesstadesrepères de lavigne. Revue Suisse de Viticulture, Arboriculture et Horticulture, Nyon, v. 25, n. 1, p. 7-9, 1993. 
BARRATT, D. H. P.; DERBYSHIRE, P.; FINDLAY, K.; PIKE, M.; WELLNER, N.; LUNN, J.; FEIL, R.; SIMPSON, C.; MAULE, A. J.; SMITH, A. M. Normal growth of Arabidopsis requires cytosolic invertase but not sucrose synthase. Proceedings of the National Academy of Sciences of the United States of America, Washington, DC, v. 106, n. 31, p. 13124-13129, 2009.

BASSOI, L. H.; DANTAS, B. F.; LIMA FILHO, J. M. P.; LIMA, M. A. C.; LEÃO, P. C. S.; SILVA, D. J.; MAIA, J. L. T.; SOUZA, C. R. Preliminary results of a long term experiment about RDI and PRD irrigation strategies in winegrape in São Francisco Valley, Brazil. Acta Horticulturae, Leuven, n. 754, p. 275-282, 2007.

BOGEAT-TRIBOULOT, M. B.; BROSCHE, M., RENAUT, J.; JOUVE, L.; LE THIEC, D.; FAYYAZ, P.; VINOCUR, B.; WITTERS, E.; LAUKENS, K.; TEICHMANN, T.; ALTMAN, A.; HAUSMAN, J. F.; POLLE, A.; KANGASJARVI, J.; DREYER, E. Gradual soil water depletion results in reversible changes of gene expression, protein profiles, ecophysiology, and growth performance in Populus euphratica, a poplar growing in arid regions. Plant Physiology, Minneapolis, v. 143, n. 2, p. 876-892, 2007.

BRADFORD, M. M. A rapid and sensitive method for quatification of microgram quantities of protein utilizing the principle of protein-dye binding. Analytical Biochemistry, New York, v. 72, p. 248-254, 1976.

CHAVES, M. M. Effects of water deficits on carbon assimilation. Journal of Experimental Botany, Oxford, v. 42, n. 234, p. 1-16, 1991.

DANTAS, B. F.; RIBEIRO, L. de S.; PEREIRA, M. S. Teor de açúcares solúveis e insolúveis em folhas de videiras, cv. syrah, em diferentes posições no ramo e épocas do ano. Revista Brasileira de Fruticultura, Jaboticabal, v. 29, n. 1, p. 42-47, 2007.

DANTAS, B. F.; RIBEIRO, L. S.; LUZ, S. R. S.; LIMA FILHO, J. M. P.; LIMA, M. A. C.; SOUZA, C. R.; BASSOI, L. H. Foliar carbohydrate content and invertase activity of 'Syrah' and 'Moacato Canelli' vines subjected to partial rootzone drying and regulated deficit irrigation. Acta Horticulturae, Leuven, n. 754, p. 301-308, 2007.

DANTAS, B. F.; RIBEIRO, L. S.; SILVA, A. P.; LUZ, S. R. S. Foliar carbohydrates content and invertase activity in vines at São Francisco River Valley - Brazil. Revista Brasileira de Fruticultura, Jaboticabal, v. 27, n. 2, p. 198-202, 2005.

DAVIES, C.; ROBINSON, S. P. Sugar accumulation in grape berries: cloning of two putative vacuolar invertase DNAs and their expression in grapevine tissues. Plant Physiology, Minneapolis, v. 111, n. 1, p. 275-283, 1996.
DELOIRE,A.; CARBONNEAU,A.; WANG, Z.; OJEDA, H. Vine and water: a short review. Journal International des Sciences de la Vigne et du vin, Bordeaux, v. 38, n. 1, p. 1-13, 2004.

DREIER, L. P.; HUNTER, J. J.; RUFFNER, H. P. Invertase activity, grape berry development and cell compartmentation. Plant Physiology \& Biochemistry, New Delhi, v. 36, 12, p. 865-872, 1998.

EFEOGLU, B.; EKMEKÇI, Y.; ÇIÇEK, N. Physiological responses of three maize cultivars to drought stress and recovery. South African Journal of Botany, Pretoria, v. 75, n. 1, p. 34-42, 2008.

ENDO, M.; NAKAGAWA, H.; OGURA, N.; SANTO, $\mathrm{T}$. Size and levels of mRNA for acid invertase in ripe tomato fruit. Plant Cell Physiology, Oxford, v. 31, n. 5, p. 655-659, 1990.

GREINER， S.; RAUSCH， T.; SONNEWALD， U.; HERBERS, K. Ectopic expression of a tobacco invertase inhibitor homolog prevents cold-induced sweetening of potato tubers. Nature Biotechnology, New York, v. 17, n. 7, p. 708-711, 1999.

HAMMOND, J. P.; WHITE, P. J. Sucrose transport in the phloem: integrating root responses to phosphorus starvation. Journal of Experimental Botany, Oxford, v. 59, n. 1, p. 93-109, 2008.

HSIAO, T. C. Measurements of plant water status. In: STEWART, B. A.; NIELSEN, D. R. (Ed.). Irrigation of agricultural crops. Madison: American Society of Agronomy, 1990. p. 244-280.

JAIN, A. K.; BASHA, S. M.; LORENZO, A. B.; LU, J.; LEONG, S. Variation in the sugar accumulation pattern of muscadine grape genotypes. Proceedings of the Florida State Horticultural Society, Goldenrod, n. 115, p. 329-336, 2002.

JIN, Y.; NI, D. A.; RUAN, Y. L. Post translational elevation of cell wall invertase activity by silencing its inhibitor in tomato delays leaf senescence and increases seed weight and fruit hexose level. The Plant Cell, Rockville, v. 21, n. 7, p. 2072-2089, 2009.

KALA, S.; GODORA, A. K. Effect of moisture stress on leaf total proteins, proline and free amino acid content in commercial cultivars of Ziziphus mauritiana. Journal of Scientific Research Banaras Hindu University, Uttar Pradesh, v. 55, n. 7, p. 65-69, 2011.

KIRSCHBAUM, M. U. F. Recovery of photosynthesis from water stress inEucalyptus pauciflora: a process in two stages. Plant Cell \& Environment, Oxford, v. 11, n. 8, p. 685-694, 1988. 
KOUNDOURAS, S.; MARINOS, V.; GKOULIOTI, A.; KOTSERIDIS, Y.; VAN LEEUWEN, C. Influence of vineyard location and vine water status on fruit maturation of nonirrigated cv. agiorgitiko (Vitis vinifera 1.). Effects on wine phenolic and aroma components. Journal of Agricultural and Food Chemistry, Easton, v. 54, n. 14, p. 5077-5086, 2006.

LARA, M. E. B.; GARCIA, M. G.; FÁTIMA, T.; EHNESS R.; LEE, T. K.; PROELS, R.; TANNER, W.; ROITSCH, T. Extracellular invertase is an essential component of cytokinin-mediated delay of senescence. The Plant Cell, Rockville, v. 16, n. 5, p.1276-1287, 2004.

LOBATO, A. K. S.; OLIVEIRA NETO, C. F.; COSTA, R. C. L.; SANTOS FILHO, B. G., CRUZ, F. J. R.; LAUGHINGHOUSE IV, H. D. Biochemical and physiological behavior of Vigna unguiculata (L.) Walp. under stress during the vegetative phase. Asian Journal of Plant Sciences, Pakistan, v. 7, n. 1, p. 44-49, 2008.

MATTHEWS, M. A.; KRIEDEMANN, P. E. Water deficit, yield, and berry size as factors for composition and sensory attributes of red wine. In: PROCEEDINGS OF THE AUSTRALIAN SOCIETY OF VITICULTURE AND OENOLOGY, 2006, Victoria. Proceedings... Victoria: ASVO, 2006. p. 1-9.

MILLER, G. L. Use of dinitrosalicylis acid reagent for determination of reducing sugars. Analytical Chemistry, Washington, DC, v. 31, n. 4, p. 426-428, 1959.

MORRIS, D. L. Quantitative determination of carbohydrates with drywood'santhrone reagent. Science, Washington, DC, v. 107, n. 1, p. 254-255, 1948.

NAIDU, B. P.; PALEG, L. G.; JONES, G. P. Nitrogenous compatible solutes in drought stressed Medicago spp. Phytochemistry, New York, v. 31, n. 4, p. 1195-1193, 1992.

OJEDA, H.; DELOIRE, A.; CARBONNEAU, A. Influence of water deficits on grape berry growth. Vitis, Siebeldingen, v. 40, n. 3, p. 141-145, 2001.

PALliOTTI, A.; CARTECHINI, A. Developmental changes in gas exchange activity in flowers, berries, and tendrils of field-grown Cabernet Sauvignon. American Journal of Enology and Viticulture, Davis, v. 52, n. 4, p. 317-323, 2001 .

PAZ, N. E.; AGUIRRE, F. M.; ONTIVEROS, J. L. R. Efecto del déficit hídrico enelpatrónelectroforético de proteínas totalesen dos variedades de maíz. Revista Fitotecnia Mexicana, Montecillo, v. 24, n. 1, p. 121-128, 2001.
PETER, B.; STEPHANIE, D. Sugar accumulation in tomato and partial purification of buffer insoluble invertase. Phytochemistry, New York, v. 36, n. 4, p. 837 884, 1994.

QUEREIX, A. Analyse et modélisation du fonctionnementstomatique de lavigne Vitis vinifera L. 2001. Thèse (Doctorat) - Université de Bordeaux, Bordeaux.

ROSS, H. A.; DAVIES, H. V.; BURCH, L. R.; VIOLA, R.; MCRAE, D. Developmental changes in carbohydrate content and sucrose degrading enzymes in tuberisingstolons of potato (Solanum tuberosum). Physiology Plantarum, Copenhagen, v. 90, n. 4, p. 748756, 1994.

RUAN, Y. L.; JIN, Y.; YANG, Y. J.; LI, G. J.; BOYER, J. S. Sugar input, metabolism, and signaling mediated by invertase: roles in development, yield potential, and response to drought and heat. Molecular Plant, Oxford, v. 3, n. 6, p. 942-955, 2010.

RUAN, Y. L.; LLEWELLYN, D. J.; FURBANK, R. T. Suppression of sucrose synthase expression represses cotton fibre cell initiation, elongation and seed development. The Plant Cell, Rockville, v. 15, n. 4, p. 952-964, 2003.

SANTOS, C. F.; LIMA, G. P. P.; MORGADO, L. B. Tolerância e caracterização bioquímica em feijão-caupi submetido a estresse hídrico na pré-floração. Naturalia, Rio Claro, v. 33, p. 34-44, 2010.

SERGEEVA, L. I.; KEURENTJES, J. J. B.; BENTSINK, L.; VONK, J.; VAN DER PLAS, L. H. W.; KOORNNEEF, M.; VREUGDENHIL, D. (2006) Vacuolar invertase regulates elongation of Arabidopsis thaliana roots as revealed by QTL and mutant analysis. Proceedings of the National Academy of Sciences of the United States of America, Washington, v. 103, n. 8, p. 2994-2999, 2006.

SILVA, J. C.; ALVES, J. D.; ALVARENGA, A. A.; MAGALHÃES, M. M.; LIVRAMENTO, D. E.; FRIES, D. D. Invertase and sucrose synthase activities in coffees plants sprayed with sucrose solution. Scientia Agricola, Piracicaba, v. 60, n. 2, p. 239-344, 2003.

SOUZA, C. R.; BASSOI, L. H.; LIMA FILHO, J. M. P.; SILVA, F. F. S.; VIANA, L. H.; DANTAS, B. F.; PEREIRA, M. S.; RIBEIRO, P. R. A. Water relations of field-grown grapevines in the São Francisco Valley, Brazil, under different rootstocks and irrigation strategies. Scientia Agricola, Piracicaba, v. 66, n. 4, p. 436-446, 2009. 
SOUZA, T. P. A. Efeitos da disponibilidade hídrica na fisiologia e produção de vitis vinifera L. Na região demarcada do douro. 2010. Tese (Doutorado em Ciências Agronômicas) - Universidade de Trás-os-Montes e Alto Douro, Vila Real.

STITT, M.; VON SCHAEWEN, A.; WILLMITZER, L. Sink regulation of photosynthetic metabolism in transgenic tobacco plants expressing yeast invertase in their cell wall involves a decrease of the Calvin cycle enzymes and an increase of glycolytic enzymes. Planta, Berlin, v. 183, n. 1, p. 40-50, 1990.

STURM, A. Invertases: primary structures, functions and roles in plant development and sucrose partitioning. Plant Physiology, Minneapolis, v. 121, n. 1, p. 1-7, 1999.

TANG, G. Q.; LUSCHER, M.; STURM, A. Antisense repression and vacuolar and cell wall invertase in transgenic carrot alters early plant development and sucrose partitioning. The Plant Cell, Rockville, v. 11, n. 2, p. 177-189, 1999.
WANG, Z. P.; DELOIRE, A.; CARBONNEAU, A.; FEDERSPIEL, B.; LOPEZ, F. An in vivo experimental system sugar phloem unloading in ripening grape berries during water deficiency stress. Annals of Botany, London, v. 92 , n. 4, p. 523-528, 2003.

ZANOR, M. I.; OSORIO, S.; NUNES-NESI, A.; CARRARI, F.; LOHSE, M.; USADEL, B.; KUHN, C.; BLEISS, W.; GIAVALISCO, P.; WILLMITZER, L.; SULPICE, R.; ZHOU, Y, H.; FERNIE, A. R. RNA interference of LIN5 in Solanumly copersicum confirms its role in controlling Brix content, uncovers the influence of sugars on the levels of fruit hormones and demonstrates the importance of sucrose cleavage for normal fruit development and fertility. Plant Physiology, Minneapolis, v. 150, n. 3, p. 1204-1218, 2009. 
